\title{
We know what we are, but not what we may be
}

DENNIS SCHAUFFER

\begin{abstract}
This essay attempts to trace a personal journey from a liberal humanist stance to an awareness of non-dualism within the altering landscape of contemporary advances in technology. My fundamental argument is that the single inimitable characteristic of human consciousness is an ability to encompass non-dual thought and that this capacity can a priori not be copied, scanned or uploaded into an informational matrix that operates through bi-polar antimonies.
\end{abstract}

Keywords: Non-dualism, technology, bi-polar antimonies, posthuman, cyborgs, transhumanism, linear logic, virtual reality, Umuntu ngumuntu ngabantu.

Most of my life has been spent in the field of Drama and Theatre Studies. More recently I moved to the Vaal University of Technology to a Principal Lectureship in Visual Arts and Design. All of my academic life then has been in the Humanities and Human Sciences and my personal stance was that of a liberal humanist. However, confronting the implications of possible and apparently imminent Posthumanism, I have had pause to reconsider my position. What follows is an attempt to trace that journey.

I begin with Katherine Hayles who, in her book How we became Posthuman, articulates her understanding of the term 'posthuman' as follows:

I understand human and posthuman to be historically specific constructions that emerge from different configurations of embodiment, technology, and culture. My reference point for human is the tradition of liberal humanism; the posthuman appears when computation rather than possessive individualism is taken as the ground of being, a move that allows the posthuman to be seamlessly articulated with intelligent machines. ${ }^{1}$

* Prof. Dennis Schauffer is an emeritus Professor of Drama and Theatre Studies at the University of KwaZulu Natal and is currently Principal Lecturer in Visual Arts and Design at the Vaal University of Technology, Gauteng, South Africa.

1 K Hayles, How we became posthuman: virtual bodies in cybernetics, literature, and informatics, (University of Chicago Press, London, 1999), pp. 33-34.

TD: The Journal for Transdisciplinary Research in Southern Africa, Vol. 2 no. 2, December 2006, pp. 379-390. 
In answer to the moral and ethical concerns that are being anticipated by this possible fundamental shift in mankind's ontology, academics such as Verner Vinge point out that this would be no more than the natural and historical human tendency to entropy; the propensity to push the boundaries of human possibilities for complexity of order and enhancement of intellectual capacity. In 1993 he wrote in a web article:

\section{Within thirty years, we will have the technological means to create superhu-} man intelligence. Shortly after, the human era will be ended. ${ }^{2}$

What then, one might ask, supersedes humans? Dualists of course will regard this entire discussion as absurd because human consciousness, they aver, is socially constructed. In addition the 'spirit', 'soul', or 'life force' are of supernatural origin and not 'embodied' in the human brain. It would, in consequence, be impossible for man to transplant or replicate human consciousness. Vitalists would say that uploading was a priori impossible.

The original cyborg (cybernetic organism) anticipated by Heidegger involved a human being with bodily functions enhanced and controlled by technological devices. Already we are familiar with pacemakers (artificial heart valve pumps) and at many centres experiments with and research into the use of nanotechnology has commenced. The race is on to produce a nanobot (a microscopic robot built by means of nanotechnology) ${ }^{3}$ to undertake simple internal operations within animal and then human bodies.

Of course the scale of the prototypes at the moment is far from being 'nano' (one billionth of a meter in size) and it will require the achievement of practically applied nanotechnology in molecular manufacturing in order for molecule-by-molecule manufacture of nanobots small enough to be injected into the human body, there to replicate themselves in sufficient numbers to maintain, repair, diagnose, cure and even enhance bodily features and functions.

Some commentators have begun to ring alarm bells by asking what would happen if the process of self-replication went out of control? If this led to the destruction of the human host this would be referred to as the 'grey goo' scenario. If the process led to the take-over of the natural ecology, then reference would be made to the 'black goo' scenario. Alan Goldstein in a very readable posting in a blog on the $I$,

2 V Vinge,. The coming technological singularity: how to survive in the Post-Human (sic.) Era. Paper presented at VISION-21 Symposium sponsored by NASA Lewis Research Center and the Ohio Aerospace Institute, March 30-31, 19931993 [online]. Available at http://www-rohan.sdsu.edu/faculty/vinge/misc/singularity.html. (Accessed 2006.06.14.)

3 See Massachusetts Institute of Technology as an important example. 
Nanobot - New Scientist - tribe.net refutes the idea of tiny robots being used for the above purposes. It is surmised:

(T)hey will not be tiny robots. That mechanical fantasy, promulgated by proponents of "Drexlerian" nanotechnology who appear devoid of even the most rudimentary knowledge of chemistry, has been decisively refuted by people who actually build the components for nanobiotechnology systems. People like the late Nobel Prize-winning chemist Richard E. Smalley and the great Harvard bioorganic chemist George Whitesides ... What will really go into our bodies, or out into the environment, will be hybrid molecular devices composed of both synthetic and biological components. These 'devices' will have been fabricated to specifically exchange chemical information with biological or ecological systems, They will not be nanobots, they will be nanobiobots- and those three letters make all the difference. ${ }^{4}$

Another version of the cyborg more familiar perhaps to my 18-year old son Daniel and to my 10-year old son Devan (and only slightly less familiar to my three daughters) and to Sci-fi readers and film-goers is that which sees human consciousness in control of almost entirely replaced and enhanced electronic or mechanical body parts. This is the so-called transhuman, (e.g. Darth Vader). The difference between a transhuman and a posthuman viewed from a technological perspective would be an entity that has undergone such a degree of modification of inherited physical being as to preclude a classification under the term Homo Sapiens. Which raises a key corollary to which I shall return: what unique quality qualifies an entity to be classified as Homo Sapiens?

Before considering this, however, we need to note a more exciting or more frightening scenario, depending on one's point of view, that has gained impetus through the successful sequencing of the human genome. Some now entertain the possibility of 'uploading' the consciousness and mental structure of a human brain for downloading into an electronic or informational matrix- in other words the dawn of sentient machines.

Apart from the dualist objections mentioned above there are other sceptics who feel that the task of uploading a human brain is of such a complex order as to place this forever beyond human technology. Whilst no one can be certain that this task will ever be achieved the possibility does seem to gain credibility from steps in this direction either already taken, or envisaged. In 1954 Vladimir Demikhov grafted the head and upper body of a puppy onto the neck of a fully grown dog. The world was shocked and morally outraged, but the US Government was also concerned that America should stay ahead of the

4 A Goldstein, "I Nanobot: Scientists are on the verge of breaking the carbon barrier" in New Scientist - tribe.net, 2006.03.09 at http://tribes.tribe.net/newscientist/thread/ af5c4f53-f81d-4ed2-a31e-cd6c3b144b4c. (Accessed 2006.06.26. Re-accessed 2006.12.05.)

TD, 2(2), December 2006, pp. 379-390. 
game in all scientific endeavour. Dr. $\mathrm{R}$ White studied to be a brain surgeon at Harvard Medical School and in 1960 he obtained government funding to establish a brain research centre at County Hospital in Cleveland, Ohio. In 1964 he transplanted a dog's brain into the neck of a second dog connecting it to the blood supply of the host animal. On 4 March 1970 White successfully transplanted the head of a decapitated rhesus monkey onto the body of another decapitated monkey. The head soon regained consciousness and attempted to bite the finger of the experimenter (an action that most people I think would applaud as being both understandable and justifiable). The spinal cord could not be attached and so the animal was in effect a paraplegic. Ray Kurzweil in Live Forever - Uploading The Human Brain ... Closer Than You Think ${ }^{5}$ makes reference to a condemned killer who in 1993 gave permission for his brain to be invasively scanned and that you can now access all ten billion bytes of him on the internet. Whilst you can see every neuron and every neurotransmitter concentration in each synapse-thin layer, the scan is not yet at a high enough resolution for a re-creation to take place. Further experiments in 1997 enabled White to achieve respiration in the receptor monkey, but the problem of attaching nerve tissue to the spinal cord remains. Recent research at the Wistar Institute of the University of Pennsylvania could point the way towards resolution of this problem. ${ }^{6}$ On 27 January 1999 a successful hand transplant from a cadaver was carried out at the Louisville Medical Centre. ${ }^{7}$ The transplantation of a human brain and human consciousness was first promoted by Marvin Minsky ${ }^{8}$ and since then it appears to be envisaged in three stages. The human head transplant would be the first step. A human brain transplant to another human host, conducted in such a way as to scan in the exact state, level, and position of every neurotransmitter, synapse, and neural connection, would be the next step. Then with the dawn of Molecular Manufacturing would come the atom by atom replication of a human brain for installation either in a human or robotic host, or into an

5 See R Kurzweil "Live forever - Uploading the human brain ... Closer than you think" in PsychologyToday.com. Published in KurzweilAI.net, 2001.04.07 at http:// www.kurzweilai.net/meme/frame.html?main=/articles/art0157.html. (Accessed 2006.09.09. Re-accessed 2006.12.05.)

6 Anon., "Regeneration in the mammalian heart demonstrated by Wistar researchers" in Science Daily, at http://www.sciencedaily.com/releases/2001/08/010807080356.htm; Anonm., "Recovery from spinal cord injury seen in mice when scarring is minimized" in ScienceDaily, 2002.01.24 at http://www.sciencedaily.com/releases/2002/01/ 020123080522.html. (Accessed 12/09/06. Re-accessed 2006.12.05.)

7 Anon., "Scientists give man a 'new' hand" in Discoverychannel.ca, 1999.01.27 at http:/ /www.exn.net/Templates/Story.asp?ID=1999012756. (Accessed 9/11/2006.11.09. Reaccessed 2006.12.05.)

8 'Conscious Machines' in Machinery of Consciousness, Proceedings, National Research Council of Canada. 75th Anniversary Symposium on Science in Society. June 1991. 
informational matrix such as a super neural computer. To date the most advanced research seems to be taking place at McGill University where Randal Koene, a doctoral student in Psychology is working on the neurological reconstruction of the hippocampus. Koene and other proponents of Mind Uploading (or Whole Brain Emulation) believe it to be possible to recreate a human life in a computer.

Ray Kurzweil, in an article for WIRED Magazine, remarks:

\begin{abstract}
One approach to designing intelligent computers will be to copy the human brain, so these machines will seem very human. And through nanotechnology, which is the ability to create physical objects atom by atom, they will have human-like - albeit greatly enhanced - bodies as well. Having human origins they will claim to be human, and to have human feelings. And being immensely intelligent, they'll be very convincing when they tell us these things. ${ }^{9}$
\end{abstract}

It seems inevitable that Artificial Intelligence will soon outstrip human intelligence (if intelligence is the capacity to assimilate, order, react to, compute, and forecast data) and it is certainly possible to conceive of machines capable of reading and understanding printed hard-copy. Personally I could, even if grudgingly, entertain the possibility of a machine with uploaded human intelligence displaying, in its way, human-like feelings. Machines that play music are hardly a new phenomenon and with a set of musical parameters and definitions, why should future machines not be capable of producing entirely original works? The same goes for Drama, Fine Art, and even (when robotics reaches that stage) a dancing robot. This raises the question: Is there anything that a machine could not ultimately take over from human consciousness?

I imagine a robot playing Hamlet. I have no doubt that the robot 'performer' would be word perfect. The emotional expression revealed through tone of voice, focus, gestural and postural semiotic signs etc. could conceivably be programmed randomly to select subtle differences of interpretation ensuring that no two performances of the same role would ever be the same. Audience reception, both audible and visible, could be factored in to provide a causal link to variations of mood, pitch, pace, projection, emphasis, and so on. Performing and Visual artists, however, know instinctively that there is another level of involvement not covered by the above. I say instinctively because we are speaking in a western language that has no adequate equivalent to the eastern concept of rasa, which makes talking about the issue very problematic. The nearest I can get to interpreting this concept is to say that rasa is the inspired feeling that an artist imbeds in

9 R Kurzweil, "Brave new world: the evolution of mind in the twenty-first century" in WIRED Magazine, 1999.10.02. Located at http://www.ghandchi.com/iranscope/ Anthology/Kurzweil-BNW.htm. (Accessed 2006.09.11. Re-accessed 2006.12.05.)

TD, 2(2), December 2006, pp. 379-390. 
an artefact in such a way that it is communicated intuitively to the informed, sensitive individual that experiences the particular artefact through the emotions. From a different mindset one could pose such questions as: How could a robot access the swadharma of Hamlet? (i.e. what he is compelled to do by virtue of his fate.) Access could only be via the gunas which Rustom Bharucha defines as 'the innate psychobiological traits which are the heritage of an individual's previous lives' (Bharucha 1993:71).

Of course in a humanist debate (as I understand Humanism) such esoteric considerations are out of order, unless the concept of humanism is revisited to incorporate the metaphysical. At the end of this paper I hope to suggest an alternative way to address the problem that might be more acceptable. Rasa theory aside then, it would appear that there is an inexorable march towards humans being partially fused with or totally subsumed by machines. Hayles opposes this view and reminds us that:

\footnotetext{
Although some current versions of the posthuman point towards the antihuman and the apocalyptic, we can craft others that will be conducive to the long-range survival of humans and of the other life-forms, biological and artificial, with whom we share the planet and ourselves (1999:291).
}

Whilst this may be a comforting rejoinder, there remains a sense of unease reflected in films such as Star Wars (1983 and later), The Fly (1986), Robocop (1987 and later) and so on. It is no longer a case of boy meets girl and after suitable dramatic complications boy gets girl. Now it is a case of man makes machine and after suitable dramatic battles man conquers machines, or vice versa, or even having fallen in love the machine seeks humanity status through the acquisition of human emotion etc.

Not that the concept of human bodies fusing with non-human forms is new. The concept is as ancient as the myths and legends of our earliest civilizations. Ganesha has the head of an elephant, Pan was half man and half goat, centaurs are fusions of man with horse, a mermaid is the fusion of woman with fish, and so on.

Transmographication in literature is reasonably common with Dracula's ability to become a bat, and Renfield's ability to become a werewolf. The Dracula tale is interesting from another point of view in that, as a vampire, he is described as being un-dead. Would 'un-dead' be a suitable term to apply to those machines with uploaded human consciousness, and would they only be regarded as 'dead' if the system crashes without a backup?

It is significant to note that in myth, legend, and in literary works that precede the concept of the cyborg, the humans fuse with other living entities in the main (some with trees, the sea, mountains etc.), but not with machines created by human technology. It is not in my view 
the prospect of men fusing with machines per se that is the cause for the current unease but with the threat of alienation and displacement of the human being from a position of control and a violation of human dignity. When Galileo in the seventeenth century (1632) proposed that the earth moved around the sun and was therefore not at the centre of the universe, religious order was immediately outraged. Copernicus, some ninety years earlier, had proposed that the world was round, not flat, and that it revolved around the sun. His writings were predictably banned by the all-powerful Catholic Church and were only unbanned in 1835. Others who agreed with Copernicus were either silenced (Brahe) or arrested and burned at the stake for heresy (Giordano Bruno).The prospect of God's finest creation, man, not being at the centre was as much a challenge to orthodox belief of it's time as Darwin's Origin of the Species (1859) proved to be later. With Modernism and Humanism man was firmly in charge and responsible for the Godless world. Even the transhuman retains control, but in posthumanism, at least in one interpretation of the term, humans seemingly capitulate and vest effective control to machines. The overarching question arises again from all of this: What qualities are unique to human beings (if any)? In other words: What distinguishes human beings from all other entities? ${ }^{10}$

Without going through all the discounted definitions involving 'tool using animals', 'opposable thumbs and non-opposable big toes', 'language users', 'creatures of compassion' etc. and without a redefinition of humanism in general or a reversion to something like Kierkegardian Christian humanism, one cannot seek a metaphysical answer to the question in terms of 'soul' or 'spirit'. These scientifically un-provable concepts aside, I do believe that a possible alternative answer could be found in the non-western mindset. To have to fuse with a machine in order to achieve immortality or heightened intelligence would make no sense to a person with the kind of traditional African mindset which has already collapsed the duality of individual and society. This is captured in the expression Umuntu ngumuntu ngabantu $u^{11}$ and the connotation 'an individual is an individual in relation to their contribution to the social good'. Compare this to the individualist ideology embedded in Descartes' Cogito ergo sum. ${ }^{12}$

The duality of life and death has also been collapsed in the notion of the amadlozi (ancestors). The so-called death of a person in such be-

10 In all of this discussion the term 'man' and 'mankind' are used. The implicit sexism in the use of such terms could derive from the establishment of the Bible and Christianity with the Council of Nicaea in 325 a.d. The Nicene Creed did not accept that women had souls. The church only accepted that women had souls in 1545.

11 A person is a person because of people.

12 I think therefore I am.

TD, 2(2), December 2006, pp. 379-390. 
lief is simply a point of transition between being a person and being an ancestor. In an animist way the ancestors inhabit trees, or rivers, rocks etc. As far as heightened intelligence is concerned this can be acquired by direct reference to the ancestors via prayer, sacrifice, trance, or through dreams, or drugs. The idea would be equally illogical to anyone who believes in reincarnation as distinct from resurrection in a Christian sense. The western mindset is characterized by linear logic grounded in dualism and western religion is equally linear in the sense that it proceeds from a notion of creation to apocalyptic eschatology. ${ }^{13}$ The eastern mindset by contrast is cyclical and nondualistic in nature. In his criticism of Peter Brook's nine hour film of the great Hindu epic the Mahabharata, Bharucha comments:

\footnotetext{
If Brook had given some importance to the cyclical nature of time that pervades the Mahabharata, he would have rejected the validity of dramatizing the epic in a predominantly linear narrative. Nothing could be more foreign to the Mahabharata than linearity ... ${ }^{14}$ What one misses ... is the sense of time that transcends chronology, time that stretches to infinity ... [In Brook's film] time is truncated into blocks of action, acts and scenes that have definite beginnings and ends (Bharucha, R. 1993:75). ${ }^{15}$
}

This suggestion further illustrates the difference between linear and cyclical mindsets because for the linear mind the whole is the sum of its parts, but for the cyclical mind the part is microcosm of the whole. This differentiation of mindsets is dealt with extensively by Marimba Ani in Yurugu. Of the western mindset she writes:

Linearity was fundamental to the system of 'logic' that Aristotle introduced, which was thereafter equated with truth (Ani, M. 1994:68).

She then quotes Vernon Dixon '... [who] characterizes European

13 Whilst the phrase 'apocalyptic eschatology' is used here in the sense of 'catastrophic end of the world', and in some religions the destruction of the planet (or of all life on earth) is in some way or another predicted, this does not necessarily imply that the human race will not survive in some new form.

14 The objection could be raised of course that the Mahabharata also has a beginning and an end and, within the work there are narratives that are linear, but this is to miss the point. It confuses the pointing finger with the direction indicated. The same kind of objection is sometimes raised to Ionesco's attempt to deal with linguistic absurdity in a play such as Rhinoceros. The play script employs meaningful words in meaningful linguistic structures. The reflection of linguistic absurdity is never-the-less conveyed if one doesn't prioritize form over content. The play script should be read as a metaabsurd document in the same way as the Mahabharata should be read as a metacyclical document.

15 Earlier Bharucha suggests: 'If Brook had been concerned with the context of the Mahabharata, he might not have attempted to summarize the entire 'story' within nine hours. For an epic that is fifteen times longer than the Bible, nine hours is really not that long; in fact, it is pitifully short. To attempt an encapsulation of the Mahabharata in its entirety is a hubris of sorts, but to limit that encapsulation to nine hours is the reduction ad absurdum of theatrical adaptation. It would have been better for Brook to focus on a few scenes.' (Bharucha, R. 1993:74.) 
(Aristotelian) logic as "either/or logic" which is based on the laws of absolute contradiction, and on the exclusion of the middle ground. He says that "either/or logic has become so ingrained in Western thought that it is felt to be natural and self-evident." He contrasts European logic with what he calls the "diunital logic" of the African world-view, in which things can be "apart and united at the same time." According to this logic, something is both in one category and not in that category at the same time [Umuntu, ngumuntu, ngabantu], This circumstance is unthinkable given the European world-view.' $(O p$. cit. p. 68). Earlier she quotes De Lubicz in his description of the rational European search for universal truth as '... "research without illumination." For him the basis of all scientific knowledge or universal knowledge is intuition. Intellectual analysis is secondary and will always be, at best, inconclusive' (Op. cit. p. 67).

My point is that a human being has a choice and is capable of both linear and cyclical thought.

The kind of advanced intelligence in a super-computer that is envisioned as a download site for possible attempts to upload human consciousness would still operate through a fundamental dualism of bi-polar antimonies (opposites). In essence a computer recognizes 0 and 1 . Instruct a computer to collapse the duality and it would freeze. How then would it be possible for a computer operating on on/off signals to become non-dual in thought? My assertion is then that the human being is the only entity known currently with the capacity for non-dual, cyclical perception and thought. I believe this to be true despite John McCarthy's challenge to Hubert Dreyfus to put money on him not being able to write logical formulas for ambiguity tolerance. ${ }^{16}$ The point is that this has not as yet been achieved. When it is we are definitely in trouble! The same applies to non-linear mathematics and science because the fields still rely upon cleverly conceived computer-based numeral simulations giving insights into problems that are at present intractable.

Whether uploading will ever become a reality remains for the moment an open question, but with the example before us of Wilbur Wright, who once declared that man would never fly, we would be wise to keep an open mind on the subject. Considering also that the time between the Wright brother's famous flight and man setting foot on the moon was a mere sixty years, and the fact that technology is advancing at a demonstrably exponential rate, who knows where we will be in 2066 . I know I will be dead - whatever that means, but I, for one, will not be asking any 'Scotty' to 'beam me up'.

16 J McCarthy, "The Degenerating Research Program" 2000.01.13 at http://wwwformal.stanford.edu/jmc/reviews/dreyfus/node4.html. (Accessed 2006.-6.15. Reaccessed 2006.12.05.)

TD, 2(2), December 2006, pp. 379-390. 
In conclusion: Having placed faith and trust in the assertion that linear logic, western science, and technology can in the end explain all things western, humanists are fast approaching the position in which a 'yes' or 'no' answer will have to be given to the question: Is there any unique, inimitable quality possessed by Homo sapiens alone? A capacity for non-dual thought is what I propose ironically enough to back up a positive answer to this essentially 'dualist' question. The implications of this however are profound and, if accepted, there would be need to re-define humanism. A negative response will have equally profound implications for, with no apparent claim to any unique quality, humankind might very well be logically advised to follow the yellow brick road to the mechanical wizard that will make it possible for us to leave our human bodies to live forever an idyllic, super-intelligent, disease-free life in hedonistic virtual reality. In the dark days of man's ignorance this condition used to be referred to as Heaven, Moksha, Nirvana, or some other culture-specific term. The Posthuman version though will be a God-less existence without transmographied humans with wings. It is also useful to bear in mind that this 'yes' or 'no' answer will only be required of those with linear mindsets. The rest will be left to carry on in their non-linear, cyclical way, pursuing strangely similar though radically different ends; an entirely appropriate position to be in for a non-dualist ... myself now among that number until the inexorable tide of changing insights and awareness sweeps me away to welcome new perspectives. I wonder what a post posthuman perspective will involve?

\section{Bibliography}

\section{Published sources (Hard copy)}

ANI, M. 1994. Yurugu: An African-centered Critique of European Cultural Thought and Behavior. New Jersey: Africa World Press.

BHARUCHA, R. 1993. Theatre and the World, Performance and the politics of culture. London: Routledge.

HAWKINS, S. 1988. A brief history of time. London: Bantam.

HAYLES, K. 1999. How we became posthuman virtual bodies in cybernetics, literature, and informatics. London: University of Chicago Press.

KURZWEIL, R. 1999. The Age of Spiritual Machines. New York: Viking.

OVERTON, W.F. 2004. "Embodied development: ending the nativismempiricism debate" in COLL, C., BEARER, E., and LERNER, R. (Eds.) 2004 Nature and nurture: the complex interplay of genetic and environmental Influences on human behavior and development. (pp. 201-223). Mahwah,NJ: Lawrence Erlbaum Ass. 
RUDALL, B. H. 2004. "Innovative Systems" in Kybernete, 33(1) 2004, pp. 8-21.

SPENGLER, O. 1959. The Decline of the West. London: Allen \& Unwin.

THAPAR, R. 2002. "Cyclic and linear time in early India" in RIDDERBOS, K. (Ed.) 2002. Time. Cambridge: C.U.P.

TREFILL, J. 1997. Are we unique? New York: John Wiley.

WILSON, C. and GRANT, J. (Eds.) 1981. The directory of possibilities. Exeter: Webb \& Bower.

\section{Webliography}

ALLHOFF, F. 2005. [online] Germ-Line Genetic Enhancement and Rawlsian Primary Goods. Available at http://homepages.wmich.edu/ fallhoff/Genetic Enhancement.pdf. Accessed 2006.06.11.

GOLDSTEIN, A. 2006 [online] Available at http://tribes.tribe.net/ newscietist/thread/af5c4f53-f81d-4ed2-a31e-cd6c3b144b4c. Accessed 2006.06.24.

INSTITUTE FOR ETHICS AND EMERGING TECHNOLOGIES.[online] Blog site discussing: Human Enhancement Technologies and Human Rights. Available at http://ieet.org/index.php/IEET/ HETHR.

KURZWEIL, R. 2006.a [online] Available at http:/ /www.Kurzweilai.net/ articles/art0157.html. Accessed 2006.09.09.

KURZWEIL, R. 2006.b [Online] Brave new world: the evolution of mind in the twenty-first century. Available at http:// www.ghandchi.com/iranscope/Anthology/Kurzweil-BNW.htm. Accessed 2006.08.21.

MANSUETO, A. 1990 [online] Dialectic, Systems, and Organization: The Philosophical Implications of the New Science. The Evolution of Complexity - Abstracts. Available at http://pespmc1. vub,ac.be/Einmag_Abstr/AMansueto.html. Accessed 2006.06.15.

McCARTHY, J. 2006 [online] The Degenerating Research Program Available at http://www-formal.stanford.edu/jmc/reviews/dreyfus/ node4.html. Accessed 2006.06.15.

MORE, M. 1994 [online] On Becoming Posthuman. Available at http:/ /www.maxmore.com/becoming.htm. Accessed 2006.03.02.

PANDE, A. 2006. [online] Navarasa- An Embodiment in Indian Art. Available at_http://www.alkapande.com/acad_navrasa.htm. Accessed 2006.05.19. 
SOROKIN, A. 1998 [online] The Integral Theory of Truth and Reality. Available at http://www.intuition.org/sorokin.htm.

VINGE, V. 1993. [online] The Coming Technological Singularity:How to Survive in the Post-Human Era. Available at http://wwwrohan.sdsu.edu/faculty/vinge/misc/singularity.html. Accessed 2006.06.14.

WARWICK, K. 2000. [online] Cyborg 1.0 Available at http:// www.wired.com/wired/archive/8.02/warwick.html. Accessed 2006.05.21.

WIGHT, A.B. 1990. [online] Creation, Evolution, and the Human Genome. Available at http//www.yale.edu/ynhti/curriculum/ units/1990/6/90.06.09.x.html. Accessed 2006.06.11. 